\title{
Executive Function in Korean-English Bilingual Children with and without Vocabulary Delay
}

\author{
Dongsun Yim, Yeonjoo Jo, Jiyun Han, Jimin Seong \\ Department of Communication Disorders, Ewha Womans University, Seoul, Korea
}

Correspondence: Dongsun Yim, Ph.D Department of Communication Disorders, Ewha Womans University, 52 Ewhayeodae-gil, Seodamun-gu, Seoul 03760, Korea

Tel: $+82-2-3277-6720$

Fax: +82-2-3277-2122

E-mail: sunyim@ewha.ac.kr

Received: January 12, 2016

Revised: February 7, 2016

Accepted: February 15, 2016

This work was supported by the Ewha Womans University Research Grant of 2015.

\begin{abstract}
Objectives: The purpose of this study was to investigate whether bilingual children with and without vocabulary delay (BINL and BIVD) show different performance in working memory and shifting, which are subtypes of executive functions. Methods: Thirty-three children (19 normal language group, 14 vocabulary delay group) between 6- and 9-yearold performed Dimensional Change Card Sort (DCCS) as a shifting task, Matrix as a nonverbal working memory task, and Korean and English non-word repetition (NWR) tasks as verbal working memory tasks. For data analyses, one-way ANOVA and Pearson correlation were conducted. Results: The BIVD group performed significantly poorer than the BINL group on DCCS and Matrix, whereas no significant differences on both NWR tasks between groups was observed. The correlation analyses revealed that in the BINL group, both Korean and English composite score of receptive vocabulary were correlated with performance on Matrix and Korean NWR task, and the accuracy and reaction time of DCCS were correlated with each other. On the other hand, in the BIVD group, only Korean composite score of receptive vocabulary showed significant correlation with performance on Matrix and the English NWR task. Conclusion: the BIVD group showed poor performance on both shifting and working memory tasks compared to the BINL group. The results implicate that bilingual children with vocabulary delay have difficulties not only in the language domain but also in the non-linguistic domain. In addition, further investigation on scoring methods of linguistic tasks to bilingual children with vocabulary delay is required to generalize the findings.
\end{abstract}

Keywords: Bilingualism, Executive function, Working memory, Vocabulary delay, DCCS 집행기능(executive function)이란 정보처리를 계획하고 실행하 는 데에 관여하는 다양한 인지능력을 포괄하는 상위 인지능력이 다(Welsh \& Pennington, 1988; Zelazo \& Frye, 1997). 학자에 따라 집행기능의 하위기능을 다르게 구분하나, Miyake 등(2000)에 따르 면 집행기능은 작업기억(working memory), 억제(inhibition), 전환 (switching)의 세 가지 하위기능으로 분류된다.

억제조절기능은 목표를 달성하기 위한 인지처리과정 시 반응을 적절히 억제하고 조절하는 기능이다(Barkley, 1997). 억제조절을 평가하기 위한 과제로는 정지신호과제(stop signal task; Logan \& Cowan, 1984)가 있으며, 목표자극에서는 반응하고 목표자극이 아 닐 경우 반응하지 않아야 하는 과제이다. 억제조절 과제에서 언어
발달지연 아동은 정상 발달 아동보다 억제조절이 제한된 것으로 보고되었다(Henry, Messer, \& Nash, 2012; Spaulding, 2010).

작업기억은 정보를 일시적으로 저장하고 조작하는 데 관여하는 정보처리기제이자 언어발달기제로 알려져 있으며, 그 용량은 제한 적이라고 알려져 있다(Baddeley \& Hitch 1974; Baddeley, 1992). 언 어발달이 지연된 아동의 경우 그들의 언어적 결함은 제한된 작업 기억 용량에 기인한다고 보는 연구들이 있으며(Daneman \& Carpenter, 1980; Gaulin \& Campbell, 1994; Kohnert, Winsor, \& Yim, 2006; Leonard et al., 2007; Montgomery, 2000), 선행연구에서는 언어성 작업기억과 비언어성 작업기억에서 언어발달지연 아동이 일반아동과 비교하여 현저히 낮은 수행을 보인다고 보고하였다 
(Bishop, 2006; Leonard et al., 2007). 그러나 언어발달지연 아동과 일반아동은 시공간 스케치패드와 같은 비언어적 작업기억에서 수 행력의 차이가 있지 않다는 연구 결과가 있어(Archibald \& Gathercole, 2006; Williams, Stott, Goodyer, \& Sahakian, 2000), 작업기억 에서 이중언어사용 언어발달지연 아동의 수행을 지속적으로 검토 해야할 필요가 있다.

작업기억은 음운적 작업기억과 관련 있는 음운루프(phonological loop), 시공간적 작업기억과 관련 있는 시공간 스케치패드(visuospatial sketchpad), 그리고 하위체계로부터 정보를 통합하고 관 리하는 상위체계인 중앙 집행기능(central executive function)의 세 가지 하위 요소로 구분할 수 있다(Baddeley, 1992). 이러한 작업 기억 중 음운적 작업기억을 평가하는 대표적인 과제로는 비단어 따라말하기가 있으며(non-word repetition; Gathercole \& Baddeley, 1990), 이 과제는 이중언어 사용자를 대상으로 한 많은 선행연구에 서 이미 음운적 작업기억을 측정하는 과제로서 그 효용성이 검증 되었다(Gutierrez-Clellen \& Simon-Cereijido, 2010; Windsor, Kohnert, Lobits, \& Pham, 2010). 특히 언어발달지연 아동은 일반아동 에 비해 음운규칙 처리 및 회상에 어려움을 보여 언어성 작업기억 에서의 한계가 있음이 보고된 바 있다(Briscoe, Bishop, \& Norbury, 2001; Caplan \& Waters, 1999; Eadie, Fey, Douglas, \& Parsons, 2002; Gathercole \& Baddeley, 1990; Swanson \& Sachse-Lee, 2001).

또한 시공간 스케치패드를 측정하는 과제로는 매트릭스(Gathercole \& Pickering, 2000)가 주로 사용되며 매트릭스는 동일한 크 기로 분할된 $3 \times 3$ 행렬 안에서 순차적으로 제시되는 시각적 자극을 기억하여 저장 및 인출을 요구하는 과제이다(Yim, Kim, \& Yang, 2015). 언어발달지연 아동은 매트릭스 과제를 통해 시공간 스케치 패드에서 어려움이 두드러지는 것으로 보고되었으며(Bishop, 2006; Leonard et al., 2007), 이러한 정보처리능력의 결함이 언어발달지연 아동의 언어적 특성을 설명해 줄 수 있다고 보고되고 있다(Doehring, 1960; Montgomery, 1993; Poppen, Stark, Eisenson, Forrest, \& Wertheim, 1969). 그러나 시공간 스케치패드와 같은 비언어적 작업 기억에서 언어발달지연 아동과 일반아동의 수행 차이에 대해 입장 을 다르게 표명하고 있는 선행연구가 있어(Archibald \& Gathercole, 2006; Williams et al., 2000), 그 의견이 분분하다.

또 다른 집행기능의 하위영역 중 전환기능(switching)은 두 개 이 상의 서로 다른 개념을 동시에 전환하는 사고능력으로, 인지유연성 (cognitive flexibility)으로 볼 수 있다(Scott, 1962). 특히 언어의 전 환기능의 경우 단순히 언어 간의 전환을 일컫는 것이 아니라, 행동 을 선택하는 능력과 이를 계획하고 실행하는 데에 관여하는 집행 적 능력이 요구된다(Chee, 2006). 따라서 이러한 전환기능은 이중
언어사용 아동의 언어능력과 밀접한 관계가 있을 수 있음이 많은 선행연구를 통해서 밝혀졌다(Festman, Rodriguez-Fornells, \& Münte, 2010; Prior \& Gollan, 2011). 전환기능을 평가하기 위해서 관점전환 카드 정렬 과제(Dimensional Change Card Sort, DCCS; Zelazo, 2006)를 주로 사용하며, DCCS는 규칙이 전환 됨에 따라, 대상자가 목표 규칙에 맞게 반응을 달리해야 하는 과제이다. 주로 학령전기 아동을 위해 사용되며, DCCS점수가 높을수록 인지적 유연성이 높다는 것을 의미한다.

집행기능은 언어정보를 처리하고 기존의 언어적 지식을 조작하 는 데에 관여하며, 더 나아가 언어산출 시 자기통제(self-control), 자 기지시(self-direction), 문제 해결을 하는 데 중요한 역할을 한다(Wertsch, 1998; Vigotsky, 1962). 집행기능은 언어의 음운, 형태, 의미적 측면과 깊은 연관이 있을 뿐만 아니라 언어학습에 있어서도 중요한 역할을 하기 때문에(Meltzer, 1993; Zimmerman, 1994) 언어능력 과 상관이 있다고 보고되었다(Crosby \& Prescod, 2009; Finneran, Francis, \& Leonard, 2009; Gathercole \& Baddeley, 1990; Montgomery, 2003; Zelazo, 2006). 또한, 집행기능은 학령전기 아동의 문해 력, 화용언어, 마음이론, 학업성취능력 등을 예측하는 데 중요한 지 표로 보고되고 있다(Blair \& Razza, 2007; Bull, Espy, \&Wiebe, 2008; McClelland et al., 2007; Wellman, 1990). 그러나 이중언어를 사용 하는 언어발달지연 집단을 대상으로 이들의 집행기능을 일반아동 과 비교한 연구는 아직까지 그 수가 제한적이다.

최근 이중언어사용 환경이 인지능력에 긍정적인 영향을 준다는 선행연구 결과(Bialystok, 1999; Bialystok \& Martin, 2004; Carlson \& Meltzoff, 2008)를 바탕으로 이중언어 사용자들이 단일언어 사 용자와 비교하여 집행기능이 더 효율적으로 기능하는지 밝히려는 노력이 계속 되어 왔다. 또한 많은 연구에서 이중언어사용 환경이 인지 발달에 도움이 된다는 것을 밝히기 위해 이중언어 사용자와 단일언어 사용자를 대상으로 언어능력이 배제된 비언어적 과제를 사용해오고 있다(Hong \& Yim, 2014; Lee, Kim, \& Yim, 2013; Yang, Yim, \& Bae, 2015; Yang, Yim, Kim, \& Han, 2013; Yim, 2011; Yim, Kim, \& Yang, 2016; Yim \& Rudoy, 2013; Yim, Yang, \& Kim, 2015; Yim, Yoon, \& Lee, 2016). 이러한 비언어적 자극을 사용한 과제에서 이중언어사용 아동의 수행력이 단일언어사용 아동보다 높다는 것 은 이중언어사용 환경이 인지발달에 긍정적인 영향을 줄 수 있다 는 것으로 해석할 수 있다. 이는 언어환경에 따라 사용언어를 전환 해야 하는 이중언어 사용자의 경우 한 언어를 억제시키고 다른 언 어로 전환시키는 코드 전환(code-switching) 과정이 이들의 인지능 력의 긍정적인 영향을 주는 것으로 보이며(Meuter \& Allport, 1999), 여러 선행연구 결과가 이러한 주장을 뒷받침 하고 있다(Bialystok 
\& Martin, 2004; Bialystok, Craik, \& Luk, 2008; Carlson \& Meltzoff, 2008; Kovács \& Mehler, 2009). 전환기능을 측정하는 DCCS 과제를 4-5세 이중언어 및 단일언어 사용자에게 실시한 결과 이중 언어를 사용하는 4 세 아동의 수행력이 단일언어를 사용하는 5 세 수준과 비슷하였다는 연구결과가 보고된 바 있고(Bialystok, 1999), 5-6세의 단일언어사용 일반아동과 이중언어사용 일반아동을 대 상으로 DCCS과제를 시행한 결과 이중언어사용 일반아동의 수행 력이 단일언어사용 아동에 비해 높은 것으로 나타났다(Carlson \& Meltzoff, 2008). 또한 이중언어사용 환경에 있는 7개월 영아와 단 일언어사용 환경에 있는 영아를 대상으로 아동의 눈동자 움직임 (eye-tracking)을 측정하여 청각적 단서에 따라 화면에 나타날 그림 의 위치를 다르게 예측해서 반응해야하는 전환능력을 평가하였다. 그 결과 이중언어사용 환경에 있는 영아가 단일언어사용 환경에 있 는 또래 영아보다 전환능력이 뛰어난 것으로 나타났다(Kovács \& Mehler, 2009).

그러나 이중언어 사용자는 집행기능 하위요소 중 억제조절과 전 환능력의 수행력이 높은 반면, 작업기억에서는 단일언어사용 아동 과 이중언어사용 아동 간의 유의한 수행차이가 없다고 보고된 바 있다(Bialystok et al., 2008). 이는 집행기능의 하위기능에서 수행의 편차가 발생할 수 있다는 가능성을 밝히고 있다(Edwards \& Christophersen, 1988). 이렇듯 많은 연구에서 이중언어 사용자와 단일언 어 사용자간 집행기능의 수행력을 검토하였으나, 언어 경험이 다양 한 이중언어사용 집단 내에서 일반아동과 언어발달지연 아동 간의 집행기능 수행력을 비교한 연구는 미흡한 실정이다.

이중언어사용 아동은 동시에 두 언어를 습득하는 동시적 이중언 어 아동(simultaneous bilingual)과 모국어(L1)를 습득한 후 제2언 어를 학습하는 순차적 이중언어 아동(sequential bilingual)이 있다. 동시적 이중언어 아동은 의사소통 의도를 표현하고 낱말 조합하는 시기에 있어서 동일 연령대의 단일언어 일반아동과 차이를 보이지 않으며, 언어발달 과정이 대체로 유사하지만(Petitto \& Holowka, 2002), 순차적 이중언어 아동은 가정에서만 모국어를 사용하고 교 육환경 또는 지역사회에서 주로 제 2 언어를 사용하므로 연령이 증 가할수록 모국어와 제 2 언어(L2)의 유창성 정도의 차이가 발생한 다. 특히 국내에서 영어의 사회적 가치가 높아짐에 따라 조기영어교 육이 확산되고 있고, 3 세 이후에 교육기관에서 영어를 습득하는 순 차적 이중언어 사용자에 대한 언어발달상의 문제가 사회적으로 관 심을 모으고 있으며(Lee \& Lee, 2005) 계속적으로 해당 인구가 증 가할 것으로 예상되고 있다. 하지만 이중언어사용 아동의 언어발달 적 특성으로 인해 단일언어 사용자를 위한 규준을 제공하는 표준 화 언어검사도구로 이중언어사용 아동의 언어능력을 평가하는 것
은 그 결과를 신뢰하기 어렵다. 표준화 언어검사도구 특성상 단일 언어 사용자의 연령, 지역, 어휘출현빈도, 문항 난이도 등을 고려하 여 규준이 구성되어 있기 때문에 다양한 언어와 문화적 환경에서 자란 이중언어사용 아동에게 적용하는 데에 한계가 있다. 또한 각 언어 영역에서 표면적으로 나타나는 현행수준을 단일언어사용 또 래와 비교하는 것은 자칫 이중언어사용 아동이 언어장애로 보일 수 있는 위험이 따른다(Gutierrez-Clellen \& Pena, 2001).

따라서 이중언어사용 아동의 언어장애 유무를 판별할 때에 언 어능력뿐만 아니라 집행기능과 같은 인지능력에서 결함을 동반하 는지 검토하는 것이 필요하며, 더 나아가 집행기능과 언어능력 간 의 관계를 확인할 필요가 있다. 이중언어사용 언어발달지연 아동도 단일언어사용 언어발달지연의 아동과 마찬가지로 정보처리 영역에 서 결함을 보인다고 검토한 선행연구를 바탕으로(Kohnert, Windsor, \& Ebert, 2009) 집행기능과 같은 상위 인지능력에서 이중언어 사용 언어발달지연 아동의 수행을 검토하여 인지능력에서 결함을 뒷받침할 근거가 필요하다. 이에 따라 본 연구는 집행기능을 구성 하는 하위요소 중 언어성 작업기억과제인 비단어 따라말하기, 비언 어성 작업기억과제인 매트릭스, 그리고 전환기능과제인 DCCS를 사용하여 이중언어사용 어휘발달지연 아동과 일반아동 간의 수행 을 비교하고자 하였다. 본 연구의 연구질문은 다음과 같다.

1. 집행기능 하위 요소 중 언어적 작업기억과제인 비단어 따라말 하기와 비언어적 작업기억과제인 매트릭스, 그리고 전환기능 과제인 DCCS에서 이중언어사용 일반아동과 이중언어사용 어휘발달지연 아동 간의 수행력에 유의한 차이가 있는가?

2. 각 집단(이중언어사용 일반아동, 이중언어사용 어휘발달지연 아동) 내 언어능력과 집행기능 하위요소 간에 유의한 상관이 있는가?

\section{연구 방법}

\section{연구대상}

본 연구는 서울 및 경기 지역에 거주하는 만 6-9세의 이중언어 일 반아동 19 명, 이중언어 어휘발달지연 14 명 총 33 명을 대상으로 하였 다. 본 연구에 참여한 한국어-영어 이중언어 아동의 선정기준은 이 중언어의 기능적 정의를 따라(Kohnert, 2008; Hong \& Yim, 2014) (1) 국내 또는 국외에서 출생하여 모국어인 한국어를 습득하고 3세 이후에 영어를 습득한 순차적 이중언어사용 아동으로(McLaughlin, 1995), (2) 가정에서 형제, 부모 또는 부모 중 한 명과 고정적으로 한국어를 사용하며, (3) 영어 유치원 또는 국제 교육기관에 재학 중 으로 하루 평균 5 시간 이상 또래아동과 상호작용 및 교육프로그램 
에서 영어를 사용하는 아동이고, (4) 카우프만 아동용 지능검사 (Korean Kaufman Assessment Battery for Children, K-ABC; Moon \& Byun, 2003) 결과 동작성 지능 표준점수가 85점 이상, (5) 알버타 언어 및 발달 부모설문지(Alberta Language and Development Questionnaire, ALDeQ; Paradis, Emmerzael, \& Duncan, 2010) 결과 -1 $\mathrm{SD}$ 이상, (6) 수용·표현 어휘력검사에서 수용어휘력(Receptive \& Expressive Vocabulary Test, REVT; Kim, Hong, Kim, Jang, \& Lee, 2009)과 Peabody Picture Vocabulary Test-IV (PPVT-IV; Dunn, \& Dunn, 2007) 합산점수 산출결과, 수용어휘력 점수가 두 검사도구 에서 모두 $0 \mathrm{SD}$ 이상, (7) 신체, 감각, 정서, 행동 등의 기질적 문제를 동반하지 않은 아동을 대상으로 하였다.

본 연구에 참여한 이중언어사용 어휘발달지연 아동의 선정기준 은 (1) 국내 또는 국외에서 출생하여 모국어인 한국어를 습득하고 3 세 이후에 영어를 습득한 순차적 이중언어사용 아동으로서(McLaughlin, 1995), (2) 가정에서 형제, 부모 또는 부모 중 한 명과 고정 적으로 한국어를 사용하며, (3) 영어 유치원 또는 국제 교육기관에 재학 중으로 하루 평균 5 시간 이상 또래아동과 상호작용 및 교육프 로그램에서 영어를 사용하는 아동이고, (4) 카우프만 아동용 지능 검사(K-ABC; Moon \& Byun, 2003) 결과 동작성 지능 표준점수가 85점 이상, (5) 알버타 언어 및 발달 부모설문지(ALDeQ; Paradis et al., 2010) 결과 - $1.25 \mathrm{SD}$ 미만, (6) 수용·표현 어휘력검사에서 수용 어휘력(REVT; Kim et al., 2009)과 PPVT-IV (Dunn,\& Dunn, 2007) 합산점수 산출결과, 수용어휘력 점수가 두 검사도구에서 모두 -1.25 $\mathrm{SD}$ 미만, (7) 신체, 감각, 정서, 행동 등의 기질적 문제를 동반하지 않 은 아동을 대상으로 하였다. 두 집단의 부모와 아동에 관한 정보는 Table 1에 제시하였다.

이중언어사용 일반아동의 평균 생활월령은 $83.68(\mathrm{SD}=17.75)$,

Table 1. Participants' characteristics

\begin{tabular}{lcc}
\hline & BINL (N=19) & BIVD (N=14) \\
\hline Age (mo) & $83.68(17.75)$ & $85.40(18.49)$ \\
Nonverbal IO ${ }^{\mathrm{a}}$ & $114.26(9.92)$ & $104.93(18.41)$ \\
Receptive vocabulary (composite score) & & \\
REVT & $123.26(25.73)$ & $63.35(15.21)$ \\
PPVT & $139.26(21.64)$ & $76.14(17.56)$ \\
Parent's report $^{\mathrm{b}}$ & $>-1 \mathrm{SD}$ & $<-1.25 \mathrm{SD}$ \\
Duration of English exposure $^{\mathrm{c}}$ & $50.57(17.70)$ & $43.33(23.29)$ \\
\hline
\end{tabular}

Values are presented as mean (SD).

$\mathrm{BINL}=$ bilingual children with normal language; $\mathrm{BIVD}=$ bilingual with vocabulary delay; REVT=Receptive \& Expressive Vocabulary Test (Kim, Hong, Kim, Jang, \& Lee, 2009); PPVT = Peabody Picture Vocabulary Test-IV (Dunn \& Dunn, 2007). a Korean Kaufman Assessment Battery for Children (Moon \& Byun, 2003), ${ }^{\text {bAlberta }}$ Language and Development Questionnaire (Paradis, Emmerzael, \& Duncan, 2010), 'Language Social Background Questionnaire (Luk \& Bialystok, 2013).
이중언어사용 어휘발달지연 아동의 평균 생활월령은 $85.40(\mathrm{SD}=$ 18.49) 이며 두 집단의 차이는 통계적으로 유의하지 않았다 $(p>.05)$. 또한 동작성 지능에서 이중언어사용 일반아동 $(\mathrm{M}=114.26, \mathrm{SD}=$ 9.92)과, 이중언어사용 어휘발달지연 아동 $(\mathrm{M}=104.93, \mathrm{SD}=18.41)$ 간에 통계적으로 유의한 차이가 없었다( $p>.05)$.

본 연구에서는 이중언어사용 아동의 모국어와 영어 수용어휘력 을 평가하기 위해 수용·표현 어휘력검사(REVT; Kim et al., 2009) 중 수용어휘력 검사와 PPVT-IV (Dunn \& Dunn, 2007)를 실시하 였으며, 합산점수법(composite scoring; Core, Hoff, Rumiche, \& Señor, 2013; Gross, Buac, \& Kaushanskaya, 2014; Kohnert, 2010; Pearson, Fernandez, \& Oller, 1993)을 실시하여 원점수를 산출하였다. 합산 점수는 한국어와 영어를 모두 제시하였을 때 두 언어 모두에 서 오반응한 것만을 틀린 것으로 간주하여 원점수를 산출하는 방 법으로 두 언어 중 한 언어로 어휘의 개념(concept)을 이해하는 경 우 정반응으로 간주하였다. 문화적, 언어적으로 다양한 이중언어 사용 아동의 경우 한 언어로만 어휘를 평가하였을 때 자칫 언어장 애로 과잉 진단될 수 있는 위험이 있기 때문에(Kayser, 1995; Langdon, 1992), 이중언어사용 아동의 언어특성을 고려하여 합산점수법 을 실시하였다. 두 집단 간 수용어휘는 REVT, PPVT-IV에서 모두 유의한 차이가 있었으며 $(p<.05)$, 이중언어사용 일반아동이 이중언 어사용 어휘발달지연에 비해 수용어휘력 점수가 유의하게 높았다 (Table 1).

또한, 이중언어사용 아동의 경우 개개인의 언어경험이 다르기 때 문에 부모보고를 통해 아동의 모국어 발달력을 평가하였다(ALDeQ; Paradis et al., 2010). 또한 아동의 언어 및 사회적 배경을 검토하 기 위해 Luk와 Bialystok (2013)이 개발한 언어 및 사회적 배경 설문 지(Language Social Background)를 실시하였다. 그 결과 대상자들 의 평균 영어노출기간에서도 이중언어사용 일반아동과, 이중언어 사용 어휘발달지연 아동 간에 유의한 차이는 없었다( $p>.05$ ) (Table 1).

\section{연구도구}

이중언어사용 집단의 집행기능의 하위영역의 기능을 평가하기 위해 아래와 같은 연구과제들을 시행하였다.

\section{작업기억과제}

비언어성 작업기억과제: 매트릭스

작업기억의 하위 영역인 시공간 스케치패드의 용량과 수용언어 간의 상관을 검토한 선행연구에서 실시한 매트릭스(Gathercole \& Pickering, 2000)를 수정 및 보안하여 컴퓨터로 제시하였다. 
컴퓨터 화면에 $3 \times 3$ 으로 구성된 9 개의 흰색 매트릭스가 등장하 며, 이 흰색 매트릭스에 주황색 매트릭스가 0.5 초 간격으로 줄지어 깜빡인다. 이 주황색 매트릭스는 난이도에 따라서 깜빡이는 개수 가 점점 늘어난다. 깜빡임이 끝난 후에는 ‘정지’라는 글씨가 등장하 고 다시 처음에 등장했던 흰색 매트릭스가 나타난다. 이때, 주황색 매트릭스가 등장한 순서를 회상하여 화면을 손가락으로 짚는다. 과제는 총 4단계로 나뉘어져 있다. 주황색 매트릭스가 나타나는 개 수에 따라서 첫 번째 단계는 2 칸, 두 번째 단계는 3 칸, 세 번째 단계 는 4 칸, 마지막 단계는 5 칸으로 구성되어 있다. 문제를 풀기 전 연습 문제로 5 문항이 주어진다. 정반응은 1 점, 오반응은 0 점으로 총 18 점을 획득할 수 있으며 본 연구에서는 정반응률(\%)로 환산하여 집 단간수행을 비교하였다.

언어성 작업기억과제: 비단어 따라말하기(non-word repetition) 비단어 따라말하기-영어

영어 비단어 따라말하기 과제는 총 16 문항으로 구성되어 있으 며, 1 음절부터 4 음절까지 각각 4 문항씩 제시된다. 모든 비단어는 자음으로 시작하며 자음군(consonant cluster)은 포함하지 않는다. 1 음절 비단어는 $\mathrm{CVC}, 2$ 음절 비단어는 $\mathrm{CVCVC}$, 3 음절 비단어는 $\mathrm{CVCVCVC}$, 4 음절 비단어는 CVCVCVCVC로 구성되어 있고 총 56 개의 자음이 사용되었다. 비단어는 다음의 기준에 따라 선정되 었다. (1) 실제 영어 어휘와 유사하지 않고, (2) 발음하기 어려운 음 소 /s, z, l, r/는 제외하였으며(Shriberg \& Kwiatkowski, 1994), (3) 명 료도를 통제하기 위해 강세가 약한 음절은 포함시키지 않았고, (4) 다음절 단어 내에서는 자음과 모음이 반복되지 않게 구성되었다. 본 연구에서는 각 문항을 정확하게 따라 한 경우 1 점을 부여하여 전체 문항에서 정확하게 반응한 문항비율을 계산하는 문항정확도 (\%)와 각 문항별 정조음한 자음을 전체 자음수로 나누어 산출하 는 자음정확도(\%)로 집단 간 수행을 비교하였다. 영어 비단어 따라 말하기의 채점방식은 주로 자음정확도로 하는 것으로 알려져 있으 나 자음정확도와 문항정확도 점수 간의 상관이 높다는 선행연구 (Archibald, 2008; Archibald \& Gathercole, 2006; Estes, Evans, \& Else-Quest, 2007)에 근거하여 본 연구에서는 두 가지 점수 산출 방 식을 사용하였다. 본 과제에서 사용한 한국어 비단어는 Appendix 1 에 제시하였다.

비단어 따라말하기-한국어

한국어 비단어 따라말하기는 각 음절의 길이가 $2,3,4,5,6$ 음절 로 각 음절 당 4 문항씩 총 20 개의 문항과 91 개의 자음으로 구성되 어 있다. 한국어 비단어 따라말하기도 영어 비단어 따라말하기와
마찬가지로 문항정확도와 자음정확도로 점수를 각각 산출하여 집 단 간 수행을 비교하였다. 약한 왜곡과 첨가는 정반응으로 하되, 생 략, 대치는 오류로 보며 정반응한 음절 수에서 제외시켰다. 아동이 정반응한 후 오류로 다시 반응할 경우에도 정반응으로 채점하였 다. 비단어는 여성 원어민의 음성을 녹음하여 녹음파일로 헤드폰 을 통해 아동에게 제공하였으며, 헤드폰의 기술상의 문제 및 헤드 폰이 아동의 머리에서 흘러내리는 등의 문제가 발생했을 경우에 한 하여 1 회 더 자극을 제시하여 2 회까지 허용하였다. 분석은 영어가 능통한 언어병리학 석사과정 재학생에 의해 이루어졌다. 본 과제에 서 사용한 영어 비단어는 Appendix 2에 제시하였다.

\section{전환 과제(Dimensional Change Card Sort)}

DCCS는 전환능력을 평가하기 위한 과제이다. DCCS는 위스콘 신 카드 정렬 검사(Wisconsin Card Sorting Test; Heaton, 1993)를 컴퓨터 화면 제시방식으로 수정 후 제작된 것이다.

전환과제는 총세 단계로 나뉜다. 첫 번째는 전환이전(pre-switch) 단계이다. 전환이전 단계는 6 문항으로 구성되어 있다. 두 번째는 전 환이후(post-switch) 단계이다. 전환이후 단계도 6 문항으로 되어 있다. 마지막으로 심화단계는 12 문항으로 되어 있으며 전환이전 단 계의 규칙과 전환이후 단계의 규칙이 함께 제시된다. 전환과제에서 공통적으로 나타나는 그림자극은 빨간 토끼, 초록 토끼, 빨간 배, 초록 배이며, 4 가지 중 하나는 목표자극으로 나타나고, 2 개는 보기 자극으로 제시된다. 이러한 자극들은 단계별로 서로 다른 규칙을 가지고 나타난다. 전환 이전 단계에서는 가운데에 제시되는 목표자 극과 같은 색깔의 자극을 두 개의 보기에서 골라야 하는 '색깔게임' 이다. 전환이후 단계에서는 제시되는 목표자극과 동일한 모양의 그 림자극을 두 개의 보기 중 선택해야 하는 '모양게임’이다. 마지막 심 화 단계에서는 '색깔게임'과 '모양게임'의 규칙이 모두 등장하며 목 표자극이 네모 안에 들어가 있으면 '색깔게임, 목표자극만 제시되 는 경우 목표자극과 같은 모양을 고르는 '모양게임'의 규칙을 적용 해야 한다. 정반응은 1 점, 오반응은 0 점으로 총 24 점을 획득할 수 있고, 본 연구에서는 정반응률(\%)로 환산하여 집단 간 수행을 비교 하였다.

\section{자료분석 및 결과처리}

본 연구는 SPSS ver. 19 (SPSS Inc., Chicago, IL, USA)를 사용하 여 일원배치분산분석(one-way ANOVA)으로 집단 간 집행기능의 하위요소(전환기능, 작업기억) 수행을 비교하였다. 또한 각 집단 내 변인 간 상관을 확인하기 위해 Pearson 상관분석을 실시하였다. 

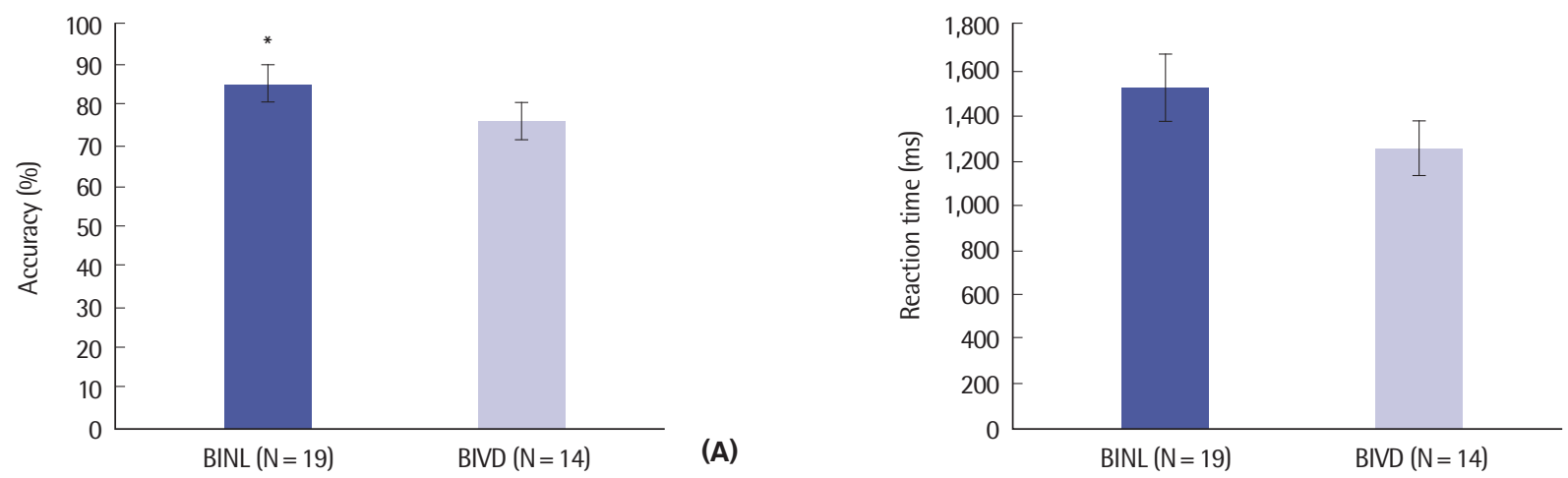

(B)

Figure 1. Comparing accuracy $(A)$ and reaction time $(B)$ between BINL (bilingual with normal language) and BIVD (bilingual with vocabulary delay) on Dimensional Change Card Sort. ${ }^{*} p<.05$

Table 2. Descriptive statistics of matrix performance

\begin{tabular}{lll}
\hline & BINL $(\mathrm{N}=19)$ & BIVD (N=14) \\
\hline DCCS_Acc (\%) & $85.26(12.24)$ & $76.00(12.69)$ \\
DCCS_RT (ms) & $1,521(647)$ & $1,252(447)$
\end{tabular}

Values are presented as mean (SD).

$\mathrm{BINL}=$ bilingual with normal language; $\mathrm{BIVD}=$ bilingual with vocabulary delay; $\mathrm{DCCS}=$ dimensional card change sorting; $\mathrm{ACC}=$ accuracy; $\mathrm{RT}=$ reaction time

Table 3. Descriptive statistics of nonverbal and verbal working memory

\begin{tabular}{lll}
\hline & BINL $(\mathrm{N}=19)$ & $\operatorname{BIVD}(\mathrm{N}=14)$ \\
\hline Matrix & $83.62(19.63)$ & $65.87(22.31)$ \\
NWR_KOR_Item & $83.42(14.04)$ & $78.57(14.73)$ \\
NWR_ENG_Item & $57.89(13.57)$ & $56.78(15.01)$ \\
NWR_KOR_PCC & $92.25(9.43)$ & $88.57(6.09)$ \\
NWR_ENG_PCC & $88.82(9.72)$ & $78.10(8.39)$ \\
\hline
\end{tabular}

Values are presented as mean (SD).

$\mathrm{BINL}=$ bilingual with normal language; BIVD= bilingual with vocabulary delay; NWR_ KOR_Item = item score of Korean non-word repetition; NWR_ENG_Item=item score of English non-word repetition; $\mathrm{PCC}=$ percentage of correct consonants.

\section{연구 결과}

\section{집행기능에서 집단 간 수행 비교}

전환과제에서 집단 간 수행 비교

집단 간 전환과제 수행에 대한 기술통계는 Table 2에 제시하였다.

두 집단 간 DCCS 과제 정확도와 반응시간을 비교한 결과, 과제 정확도에서 집단 간 차이가 통계적으로 유의하였다 $\left(F_{(1,32)}=4.473\right.$, $p<.05)$. 따라서 이중언어사용 일반아동이 이중언어사용 어휘발달 지연 아동보다 과제 정확도가 유의하게 높은 것으로 나타났다. 그 러나 반응시간에서 이중언어사용 일반아동이 이중언어사용 어휘 발달지연 아동보다 느렸으나 통계적으로 유의하지 않았다( $p>.05)$. 두 집단 간 DCCS 과제 정확도와 반응시간을 Figure 1 에 제시하였다.

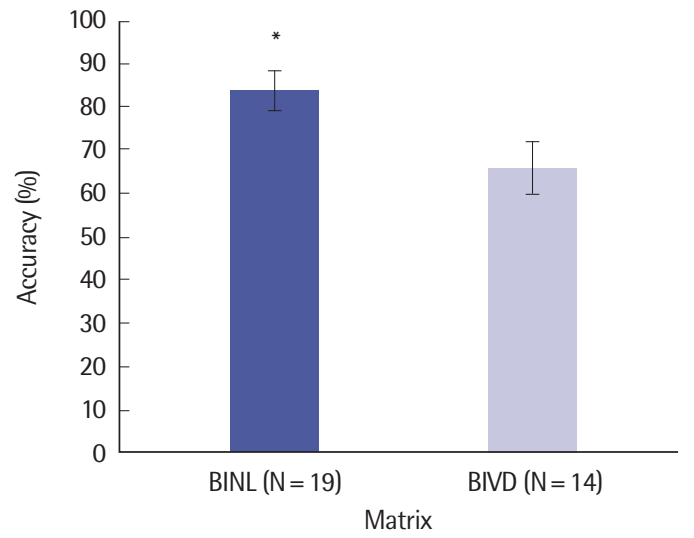

Figure 2. Matrix performances between BINL (bilingual with normal language) and BIVD (bilingual with vocabulary delay). ${ }^{*} p<.05$.

\section{작업기억에서 집단 간 수행 비교}

집단 간 비언어성 및 언어성 작업기억과제 수행에 대한 기술통계 는 Table 3에 제시하였다.

두 집단 간 비언어성 및 언어성 작업기억과제 정확도를 비교한 결 과, 비언어성 작업기억과제인 매트릭스 수행에서 집단 간 차이가 통 계적으로 유의하였다 $\left(F_{(1,31)}=5.870, p<.05\right)$. 다시 말해, 이중언어사 용 일반아동이 이중언어사용 어휘발달지연 아동보다 비언어성 작 업기억과제인 매트릭스의 과제 정확도가 유의하게 높았다. 두 집단 간 비언어성 작업기억과제 수행은 Figure 2에 제시하였다.

반면, 언어성 작업기억과제에서는 두 언어로 실시한 비단어 따라 말하기에서 점수산출 방식에 따라 집단 간 차이가 다르게 나타났 다. 문항점수로 집단 간 비단어 따라말하기 수행을 비교한 결과, 두 집단 간 수행 차이가 통계적으로 유의하지 않았다(NWR_KOR_ Item: $F_{(1,32)}=.922, p>.05$; NWR_ENG_Item: $\left.F_{(1,32)}=.049, p>.05\right)$. 그러나 자음정확도로 집단 간 비단어 따라말하기 수행을 비교한 

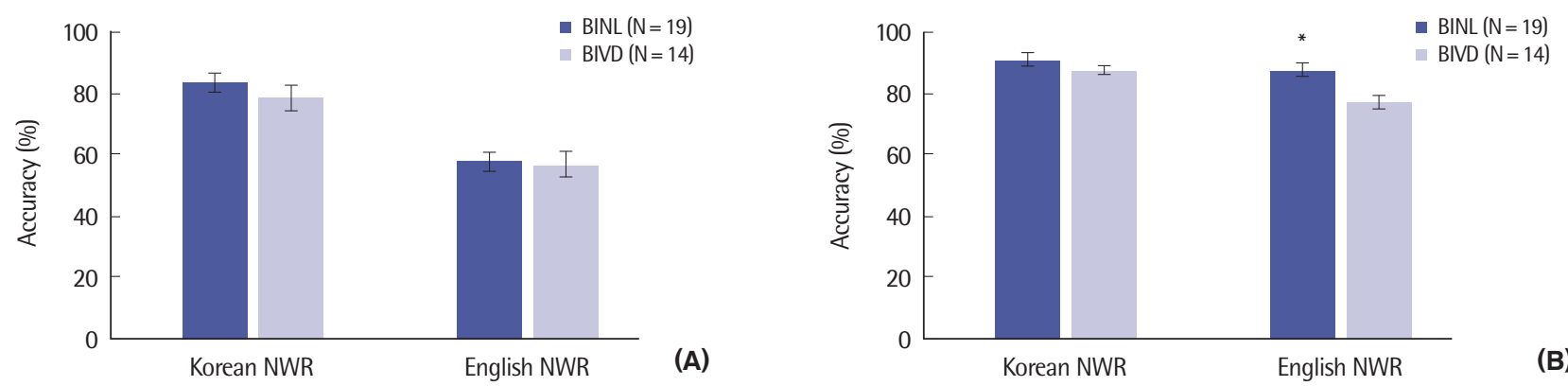

Figure 3. (A) Non-word repetition (NWR) item scores and (B) percentage of correct consonants between BINL (bilingual with normal language) and BIVD (bilingual with vocabulary delay). ${ }^{*} p<.05$.

Table 4. Correlation coefficient among tasks in bilingual children with normal language

\begin{tabular}{|c|c|c|c|c|c|c|}
\hline & REVT & PPVT & DCCS_ACC & DCCS_RT & Matrix & NWR_KOR \\
\hline PPVT & $.809^{* *}$ & & & & & \\
\hline DCCS_ACC & $.507^{*}$ & .381 & & & & \\
\hline DCCS_RT & .270 & .116 & $.737^{* *}$ & & & \\
\hline Matrix & $.590^{* *}$ & $.581^{* *}$ & .265 & .070 & & \\
\hline NWR_KOR & $.600^{* *}$ & .390 & .137 & .050 & .455 & \\
\hline NWR_ENG & .328 & .261 & .303 & -.082 & .240 & .069 \\
\hline
\end{tabular}

REVT= composite score of Receptive \& Expressive Vocabulary Test (Kim, Hong, Kim, Jang, \& Lee, 2009); PPVT= composite scoring of Peabody Picture Vocabulary Test (Dunn \& Dunn, 2007); DCCS=Dimensional Change Card Sort; ACC=accuracy; RT = reaction time; NWR_KOR=Korean version of non-word repetition (item-based scoring); NWR_ $E N G=$ English version of non-word repetition (item-based scoring).

${ }^{*} p<.05,{ }^{* *} p<.01$.

Table 5. Correlation coefficient among tasks in bilingual children with vocabulary delay

\begin{tabular}{|c|c|c|c|c|c|c|}
\hline & REVT & PPVT & DCCS_ACC & DCCS_RT & Matrix & NWR_KOR \\
\hline PPVT & $.069^{*}$ & & & & & \\
\hline DCCS_ACC & .137 & .365 & & & & \\
\hline DCCS_RT & -.041 & -.415 & $.757^{* *}$ & & & \\
\hline Matrix & $.887^{* * *}$ & -.030 & .284 & .252 & & \\
\hline NWR_KOR & .318 & .179 & .150 & .371 & .341 & \\
\hline NWR_ENG & $.763^{* *}$ & -.020 & .466 & .172 & $.789^{* *}$ & .134 \\
\hline
\end{tabular}

REVT = composite score of Receptive \& Expressive Vocabulary Test (Kim, Hong, Kim, Jang, \& Lee, 2009); PPVT= composite score of Peabody Picture Vocabulary Test (Dunn \& Dunn, 2007); DCCS = Dimensional Change Card Sort; ACC=accuracy; RT = reaction time; NWR_KOR=Korean version of non-word repetition (item-based scoring); NWR_ $\mathrm{ENG}=$ English version of non-word repetition (item-based scoring).

${ }^{*} p<.05,{ }^{* *} p<.01$.

결과, 영어 비단어 따라말하기 과제에서 두 집단 간 차이가 유의하 게 나타났다(NWR_ENG_PCC: $\left.F_{(1,33)}=11.473, p<.05\right)$. 다시 말해, 이중언어사용 어휘발달지연 집단이 이중언어사용 일반아동 집단 에 비해 영어 비단어의 자음을 정확하게 산출하는 데에 어려움이 있는 것으로 나타났다. 문항정확도와 자음정확도로 집단 간 비단 어 따라말하기 수행을 비교한 결과를 Figure 3에 제시하였다.

\section{집단 내 변인 간 상관관계}

\section{이중언어사용 일반 집단}

이중언어사용 일반집단의 집행기능 하위영역(작업기억과제, 전 환과제), 수용어휘력, 영어노출시간 간의 상관관계를 확인하기 위 해 Pearson 상관계수를 산출하였다. 결과는 Table 4 와 같다.

이중언어사용 일반 집단의 언어능력과 집행기능 하위요소 간의 상관관계를 분석한 결과, REVT 합산점수는 PPVT 합산점수 $(r=.809$, $p<.01)$, DCCS_ACC $(r=.507, p<.05)$, 매트릭스 $(r=.590, p<.01)$, 
NWR_KOR $(r=.600, p<.01)$ 와 유의한 상관을 보였으며, PPVT 합 산점수도 매트릭스 $(r=.581)$ 와 유의수준 .01에서 유의한 상관을 보 였다. 그리고 DCCS_ACC는 DCCS_RT $(r=.737, p<.01)$ 와 유의한 정적상관을 보였다. 그러나 다른 변인 간의 상관관계는 나타나지 않았다.

\section{이중언어사용 어휘발달지연 집단}

이중언어사용 어휘발달지연 집단의 어휘력과 집행기능 하위영 역(작업기억과제, 전환과제) 간의 상관관계를 검토하기 위해 Pearson 상관계수를 산출하였다. 결과는 Table 5와같다.

이중언어사용 어휘발달지연 집단의 언어능력과 집행기능 하위 요소 간의 상관관계를 분석한 결과, REVT 합산점수는 PPVT 합산 점수 $(r=.069, p<.05)$, 매트릭스 $(r=.887, p<.01)$, NWR_ENG $(r=$ $.763, p<.01)$ 와 유의한 상관을 보였으며, DCCS_ACC는 DCCS_ $\mathrm{RT}(r=.757, p<.01)$ 와 유의한 상관을 보였다. 그리고 매트릭스는 NWR_ENG $(r=.789, p<.01)$ 와 유의한 상관을 나타냈다. 그러나 다른 변인 간의 상관관계는 나타나지 않았다.

\section{논의 및 결론}

본 연구에서는 한국어-영어 이중언어사용 아동을 대상으로 언 어능력과 집행기능(전환기능, 작업기억)의 관계를 검토하고자 하였 다. 집행기능의 하위요소(전환기능, 작업기억) 과제로 DCCS와 매 트릭스, 두 언어로 된 비단어 따라말하기 과제를 사용하여 두 집단 간 수행을 비교한 결과는 다음과 같다.

첫 번째, 집단 간 전환기능과제의 수행을 비교했을 때, 이중언어 사용 일반아동이 이중언어사용 어휘발달지연 아동보다 집단 간의 차이가 유의하였고, 일반아동의 과제 정확도가 유의하게 높았다. 그러나, 반응속도에서는 이중언어사용 어휘발달지연 아동이 일반 아동에 비해 빨랐으며, 유의한 차이는 보이지 않았다. 다시 말해, 어 휘발달지연 아동이 일반아동 간에 평균반응시간에는 유의한 차이 가 없었으나, 과제 정확도에서는 일반아동의 정확도가 유의하게 높 았으며, 반응속도와 과제 정확도 간의 관계는 정적상관을 이룬다 는 결과를 확인하였다. 이러한 결과는 두 집단이 비슷한 시간 내에 과제를 수행하는 데에 있어서 그 효율성에 차이가 있으며 이중언어 사용 일반아동이 어휘발달지연 아동보다 반응시간을 의미 있게 사용한 것으로 보인다.

또한 이중언어사용 어휘발달지연 아동의 DCCS 과제 정확도가 이중언어사용 일반아동에 비해 유의하게 낮은 것은, 정보처리 시 요구되는 인지능력이 어휘발달지체 아동의 경우 일반아동과 비교
하여 제한적이라는 것을 의미하며, 주의를 집중하여 목표를 달성 하는 데에 관여하는 집행기능 중 작업기억과 전환기능이 일반아동 에 비해 비효율적이라는 선행연구 결과를 뒷받침 하는 결과이다 (Bishop, 1993; Johnston, Smith, \& Box, 1997).

두 번째, 작업기억 중 비언어적 작업기억과제(매트릭스)를 시행 한 결과, 이중언어사용 일반아동이 이중언어사용 어휘발달지연 아 동보다 과제 정확도가 유의하게 높았다. 이것은 전환기능과 마찬가 지로 비언어성 작업기억에서도 언어 능력에 따른 수행차가 있으며, 이러한 결과는 어휘발달지연 아동이 비언어성 작업기억에서 일반 아동과 비교하여 낮은 수행력을 보인다는 선행연구와 일치한다 (Bishop, 2006; Leonard et al., 2007). 따라서, 어휘발달지연 유무에 따라 이중언어사용 아동 간 집행기능 하위영역에서의 수행력 차이 는 정보처리에 관여하는 인지능력의 결함과 관련이 있는 것으로 보 인다(Paneque \& Barbetta, 2006). 이에 따라, 표면적인 언어능력으 로 이중언어사용 아동의 언어발달지연 유무를 판단하는 것은 진단 오류를 야기할 수 있으며, 이러한 오류를 최소화하기 위해 평가 시 언어능력 기저의 정보처리능력을 평가하는 과제를 도입하는 것이 필요하다(Conti-Ramsden \& Durkin, 2012).

세 번째, 집단 간 작업기억 중 언어성 작업기억과제인 비단어 따 라말하기를 시행한 결과 점수산출 방식에 따라 집단 간 수행이 다 르게 나타났다. 본 연구에서는 자음정확도와 문항정확도로 나누 어 비단어 따라말하기 과제의 점수를 산출하였다. 그 결과, 한국어 의 경우 점수산출 방식에 상관없이 이중언어사용 일반아동과 이 중언어사용 어휘발달지연 아동 간의 유의한 수행 차이가 없었다. 국내에서 진행된 연구(Hwang, 2015)에 의하면 한국어 비단어 따 라말하기에서 언어장애 아동에게는 음절정확도보다 문항정확도 가 더 민감할 수 있다고 나타났기 때문에 본 연구에서도 문항정확 도에서 두 집단의 수행 차가 나타날 것이라고 예상하였다. 그러나 두 집단의 수행은 비슷하여 차이가 없었으며 이는 광둥어 비단어 따라말하기에서 나타난 결과와 일치한다(Stokes, Wong, Fletcher, \& Leonard, 2006). 한국어 비단어 따라말하기 과제에서 기존 연구 결과와 달리 어휘발달지연 아동과 일반아동 간의 수행차이가 나타 나지 않았던 이유는 첫째, 표본 집단의 크기가 일반아동 19 명, 어휘 발달지연 아동 14 명으로 적었기 때문일 수 있다. 둘째, 영어의 경우 강세패턴, 복잡한 음운적 구조, 조음의 복잡성 등 작업기억 용량과 더불어 비단어 따라말하기 수행에 영향을 미치는 음운적 요인이 많지만 한국어의 경우 이러한 언어적 특징이 존재하지 않아 학령기 어휘발달지연 아동에게 비단어 따라말하기로 일반아동과 수행을 비교하기엔 본 과제가 민감하지 않았을 수 있다(Stokes et al., 2006). 그러나 영어의 경우 문항정확도로 실시했을 때 나타나지 않았던 
집단 간 수행의 차가 자음정확도로 산출하였을 때 나타났다. 이는 영어 비단어 따라말하기 채점방식은 자음정확도가 가장 널리 사 용되며(Coady \& Evans, 2008; Hansson, Forsberg, Löfqvist, MäkiTorkko, \& Sahlén, 2004; Ibertsson,Willstedt-Svensson, Radeborg, \& Sahlén, 2008), 영어 비단어 따라말하기 과제 채점 시 자음정확도 를 사용했을 때, 보다 더 정확한 결과를 얻는다는 선행연구의 결과 와 일치한다(Parra, Hoff, \& Core, 2011). 이처럼 이중언어사용 아동 의 언어평가 시 다양한 과제와 함께 해당 언어 특징에 맞는 채점방 식이 필요하고, 반드시 아동이 사용하는 모든 언어를 평가해야 한 다는 선행연구(Kohnert \& Derr, 2004)를 지지하고 있다.

네 번째, 상관분석 결과 선행연구를 뒷받침하는 결과가 도출되 었다. 즉, 이중언어사용 일반아동의 경우 REVT 합산점수와 비언어 적 작업기억과제(매트릭스), 한국어 비단어 따라말하기 수행 간 정 적상관관계가 나타났고, 어휘발달지연 아동의 경우 REVT 합산점 수와 영어 비단어 따라말하기 수행 간 유의한 정적상관관계가 나 타나 이중언어사용 환경에 있는 어휘발달지연 아동에게 비단어 따 라말하기를 실시할 경우 모국어(L1)와 제2언어(L2) 모두 평가해야 할 것을 권고한다.

결론적으로 이중언어사용 어휘발달지연 아동은 집행기능의 전 환기능과 비언어성 작업기억에서 정상 발달하는 이중언어사용 아 동에 비해 어려움이 있는 것으로 나타났다. 이는 이중언어사용 어 휘발달지연 아동은 정보처리 시 요구되는 인지능력이 일반아동과 비교하여 제한적이라는 것을 의미하며, 주의를 집중하여 목표를 달성하고자 하는 집행기능이 비효율적으로 기능한 것으로 보인다 (Johnston et al., 1997). 또한 집행기능 중 언어적 능력이 상대적으 로 적게 요구되는 비언어성 과제에서 집단 간 유의한 차이가 나타 나는 것은 어휘발달지연 아동에게 비언어성 정보를 처리하는 것이 더 어려울 수 있다는 선행연구의 결과와 일치한다(Johnston \& Weismer, 1983; Leonard et al., 2007; Miller, Kail, Leonard, \& Tomblin, 2001; Windsor \& Kohnert, 2004; Windsor, Kohnert, Loxtercamp, \& Kan, 2008).

또한 본 연구는 이중언어사용 아동의 사용언어, 우세언어, 언어 사용기회, 사회언어 및 개인의 언어능력에 따라 과제 수행에 차이 가 나타날 수 있음을 알 수 있었다. 본 연구의 이중언어사용 아동은 한국에 거주하며 부모와 한국어(L1)를 사용하고, 사회에서 사용 하는 언어도 한국어(L1)이지만 영어가 가지는 사회적 가치로 인하 여 교육기관에서 일정시간 동안 영어(L2)를 기능적으로 사용해야 하는 이중언어사용 아동이다. 따라서 영어권에 거주하여 영어를 사회언어로 사용하고 영어가 우세하게 자리잡은 한국어-영어 이중 언어사용 아동과 달리 본 연구에 참여한 이중언어사용 아동은 제 2
언어(L2)의 사용 기회가 그들과 다르며, 한국어가 우세하게 자라서 이중언어사용 아동을 대상으로 했던 기존의 연구결과와는 또 다 른 결과를 도출한 것으로 보인다. 그러나 본 연구에 참여한 이중언 어사용 아동의 경우 그들의 일상에서 두 언어를 사용해야만 하는 환경에 놓인 이중언어 사용자임에도 불구하고, 해당 정의에 대한 논란이 있기 때문에 이러한 논란을 해결하기 위해 후속연구에서 단일언어사용 아동과 본 과제의 수행을 비교하여 그 근거를 제시 할 필요가 있다.

\section{REFERENCES}

Archibald, L. M. (2008). The promise of nonword repetition as a clinical tool. Canadian Journal of Speech-Language Pathology and Audiology, 32, 21-28.

Archibald, L. M., \& Gathercole, S. E. (2006). Short-term and working memory in specific language impairment. International Journal of Language \& Communication Disorders, 41, 675-693.

Baddeley, A. (1992). Working memory. Science, 255, 556-559.

Baddeley, A. D., \& Hitch, G. (1974). Working memory. Psychology of Learning and Motivation, 8, 47-89.

Barkley, R. A. (1997). Behavioral inhibition, sustained attention, and executive functions: constructing a unifying theory of ADHD. Psychological Bulletin, 121, 65-94.

Bialystok, E. (1999). Cognitive complexity and attentional control in the bilingual mind. Child Development, 70, 636-644.

Bialystok, E., \& Martin, M. M. (2004). Attention and inhibition in bilingual children: evidence from the dimensional change card sort task. Developmental Science, 7, 325-339.

Bialystok, E., Craik, F., \& Luk, G. (2008). Cognitive control and lexical access in younger and older bilinguals. Journal of Experimental Psychology: Learning, Memory, and Cognition, 34, 859-873.

Bishop, D. V. M. (2006). What causes specific language impairment in children? Current Directions in Psychological Science, 15, 217-221.

Bishop, D. V. M. (1993). Annotation: autism, executive functions and theory of mind: a neuropsychological perspective. Journal of Child Psychology and Psychiatry, 34, 279-293.

Blair, C., \& Razza, R. P. (2007). Relating effortful control, executive function, and false belief understanding to emerging math and literacy ability in kindergarten. Child Development, 78, 647-663.

Briscoe, J., Bishop, D. V., \& Norbury, C. F. (2001). Phonological processing, language, and literacy: a comparison of children with mild-to-moderate 
sensorineural hearing loss and those with specific language impairment. Journal of Child Psychology and Psychiatry, 42, 329-340.

Bull, R., Espy, K. A., \& Wiebe, S. A. (2008). Short-term memory, working memory, and executive functioning in preschoolers: longitudinal predictors of mathematical achievement at age 7 years. Developmental Neuropsychology, 33, 205-228.

Caplan, D., \& Waters, G. S. (1999). Verbal working memory and sentence comprehension. Behavioral and Brain Sciences, 22, 77-94.

Carlson, S. M., \& Meltzoff, A. N. (2008). Bilingual experience and executive functioning in young children. Developmental Science, 11, 282-298.

Chee, M. W. (2006). Dissociating language and word meaning in the bilingual brain. Trends in Cognitive Sciences, 10, 527-529.

Coady, J. A., \& Evans, J. L. (2008). Uses and interpretations of non-word repetition tasks in children with and without specific language impairments (SLI). International Journal of Language \& Communication Disorders, 43, $1-40$.

Conti-Ramsden, G., \& Durkin, K. (2012). Language development and assessment in the preschool period. Neuropsychology Review, 22, 384-401.

Core, C., Hoff, E., Rumiche, R., \& Señor, M. (2013). Total and conceptual vocabulary in Spanish-English bilinguals from 22 to 30 months: implications for assessment. Journal of Speech, Language, and Hearing Research, 56, 1637 1649.

Crosby, R., \& Prescod, R. (2009). Effects of bilingualism on cognitive abilities. Annals of Gifu Shotoku Gakuen Uiversity - Faculty of Foreign Languages, $48,15-21$

Daneman, M., \& Carpenter, P. A. (1980). Individual differences in working memory and reading. Journal of Verbal Learning and Verbal Behavior, 19, $450-466$.

Doehring, D. G. (1960). Visual spatial memory in aphasic children. Journal of Speech \& Hearing Research, 3, 138-149.

Dollaghan, C., \& Campbell, T. F. (1998). Nonword repetition and child language impairment. Journal of Speech, Language, and Hearing Research, 41, 1136-1146.

Dunn, L. M., \& Dunn, D. M. (2007). Peabody Picture Vocabulary Test fourth edition. San Antonio, TX: Pearson.

Eadie, P. A., Fey, M. E., Douglas, J. M., \& Parsons, C. L. (2002). Profiles of grammatical morphology and sentence imitation in children with specific language impairment and Down syndrome. Journal of Speech, Language, and Hearing Research, 45, 720-732.

Edwards, D., \& Christophersen, H. (1988). Bilingualism, literacy and meta- linguistic awareness in preschool children. British Journal of Developmental Psychology, 6, 235-244.

Estes, K. G., Evans, J. L., \& Else-Quest, N. M. (2007). Differences in the nonword repetition performance of children with and without specific language impairment: a meta-analysis. Journal of Speech, Language, and Hearing Research, 50, 177-195.

Festman, J., Rodriguez-Fornells, A., \& Münte, T. F. (2010). Individual differences in control of language interference in late bilinguals are mainly related to general executive abilities. Behavioral and Brain Functions, 6, 1-12.

Finneran, D. A., Francis, A. L., \& Leonard, L. B. (2009). Sustained attention in children with specific language impairment (SLI). Journal of Speech, Language, and Hearing Research, 52, 915-929.

Gathercole, S. E., \& Baddeley, A. D. (1990). Phonological memory deficits in language disordered children: is there a causal connection? Journal of Memory and Language, 29, 336-360.

Gathercole, S. E., \& Pickering, S. J. (2000). Assessment of working memory in six-and seven-year-old children. Journal of Educational Psychology, 92, 377-390.

Gaulin, C. A., \& Campbell, T. F. (1994). Procedure for assessing verbal working memory in normal school-age children: some preliminary data. Perceptual and Motor Skills, 79, 55-64.

Gross, M., Buac, M., \& Kaushanskaya, M. (2014). Conceptual scoring of receptive and expressive vocabulary measures in simultaneous and sequential bilingual children. American Journal of Speech-Language Pathology, 23, 574-586.

Gutierrez-Clellen, V. F., \& Pena, E. (2001). Dynamic assessment of diverse children: a tutorial. Language, Speech, and Hearing Services in Schools, 32, $212-224$.

Gutiérrez-Clellen, V. F., \& Simon-Cereijido, G. (2010). Using nonword repetition tasks for the identification of language impairment in Spanish-English-speaking children: does the language of assessment matter? Learning Disabilities Research \& Practice, 25, 48-58.

Hansson, K., Forsberg, J., Löfqvist, A., Mäki-Torkko, E., \& Sahlén, B. (2004). Working memory and novel word learning in children with hearing impairment and children with specific language impairment. International Journal of Language \& Communication Disorders, 39, 401-422.

Heaton, R. K. (1993). Wisconsin card sorting test: computer version 2. Odessa, FL: Psychological Assessment Resources.

Henry, L. A., Messer, D. J., \& Nash, G. (2012). Executive functioning in children with specific language impairment. Journal of Child Psychology and 
Psychiatry, 53, 37-45.

Hong, S., \& Yim, D. (2014). The assessment of language impairment in bilingual children through learning and memory tasks. Communication Sciences \& Disorders, 19, 31-44.

Hwang, M. (2015). Nonword repetition of typically developing children. Communication Sciences \& Disorders, 20, 374-385.

Ibertsson, T., Willstedt-Svensson, U., Radeborg, K., \& Sahlén, B. (2008). A methodological contribution to the assessment of nonword repetition: a comparison between children with specific language impairment and hearing-impaired children with hearing aids or cochlear implants. Logopedics Phoniatrics Vocology, 33, 168-178.

Johnston, J. R., \& Weismer, S. E. (1983). Mental rotation abilities in languagedisordered children. Journal of Speech, Language, and Hearing Research, 26, 397-403.

Johnston, J. R., Smith, L. B., \& Box, P. (1997). Cognition and communication: referential strategies used by preschoolers with specific language impairment. Journal of Speech, Language, and Hearing Research, 40, 964-974.

Kayser, H. (1995). Assessment of speech and language impairments in bilingual children. In H. Kayser (Ed.), Bilingual speech-language pathology: an Hispanic focus (pp. 243-264). Clifton Park, NY: Delmar, Cengage Learning.

Kim, Y. T., Hong, G. H., Kim, K. H., Jang, H. S., \& Lee, J. Y. (2009). Receptive ¿ expressive vocabulary test (REVT). Seoul: Seoul Community Rehabilitation Center.

Kohnert, K. (2008). Second language acquisition: success factors in sequential bilingualism. ASHA Leader, 13, 10-13.

Kohnert, K. (2010). Bilingual children with primary language impairment: issues, evidence and implications for clinical actions. Journal of Communication Disorders, 43, 456-473.

Kohnert, K., \& Derr, A. (2004). Language intervention with bilingual children. In B. Goldstein (Ed.), Bilingual language development and disorders in Spanish-English speakers (pp. 311-338). Baltimore, MD: P. H. Brookes Publishing.

Kohnert, K., Windsor, J., \& Ebert, K. D. (2009). Primary or "specific" language impairment and children learning a second language. Brain and Language, 109, 101-111.

Kohnert, K., Windsor, J., \& Yim, D. (2006). Do language-based processing tasks separate children with language impairment from typical bilinguals? Learning Disabilities Research \& Practice, 21, 19-29.

Kovács, Á. M., \& Mehler, J. (2009). Cognitive gains in 7-month-old bilingual infants. Proceedings of the National Academy of Sciences, 106, 6556-6560.
Langdon, H. W. (1992). Speech and language assessment of LEP/bilingual Hispanic students. In H. W. Langdon \& L. R. L. Cheng (Eds.), Hispanic children and adults with communication disorders (pp. 201-271). Gaithersburg, MD: Aspen Publishers.

Lee, H. J., Kim, Y. T., \& Yim, D. (2013). Non-word repetition performance in Korean-English bilingual children. International Journal of Speech-Language Pathology, 15, 375-382.

Lee, K. O., \& Lee, H. R. (2005). The relationship between bilingualism and metacognitive ability. Korean Journal of Developmental Psychology, 18, 105119.

Lee, Y., Yim, D., \& Sim, H. (2012). Phonological processing skills and its relevance to receptive vocabulary development in children with early cochlear implantation. International Journal of Pediatric Otorhinolaryngology, 76, 1755-1760.

Leonard, L. B., Weismer, S. E., Miller, C. A., Francis, D. J., Tomblin, J. B., \& Kail, R. V. (2007). Speed of processing, working memory, and language impairment in children. Journal of Speech, Language, and Hearing Research, $50,408-428$.

Logan, G. D., \& Cowan, W. B. (1984). On the ability to inhibit thought and action: a theory of an act of control. Psychological Review, 91, 295-327.

Luk, G., \& Bialystok, E. (2013). Bilingualism is not a categorical variable: interaction between language proficiency and usage. Journal of Cognitive Psychology, 25, 605-621.

McClelland, M. M., Cameron, C. E., Connor, C. M., Farris, C. L., Jewkes, A. M., \& Morrison, F. J. (2007). Links between behavioral regulation and preschoolers' literacy, vocabulary, and math skills. Developmental Psychology, 43, 947-959.

McLaughlin, B. (1995). Fostering second language development in young children: principles and practices. Santa Cruz, CA: University of California.

Meltzer, L. J. (1993). Strategy use in students with learning disabilities: the challenge of assessment. In L. Meltzer (Ed.), Strategy assessment and instruction for students with learning disabilities (pp. 93-136). Austin, TX: Pro Ed.

Meuter, R. F., \& Allport, A. (1999). Bilingual language switching in naming: asymmetrical costs of language selection. Journal of Memory and Language, 40, 25-40.

Miller, C. A., Kail, R., Leonard, L. B., \& Tomblin, J. B. (2001). Speed of processing in children with specific language impairment. Journal of Speech, Language, and Hearing Research, 44, 416-433.

Miyake, A., Friedman, N. P., Emerson, M. J., Witzki, A. H., Howerter, A., \& 
Wager, T. D. (2000). The unity and diversity of executive functions and their contributions to complex "frontal lobe" tasks: a latent variable analysis. Cognitive Psychology, 41, 49-100.

Montgomery, J. W. (1993). Haptic recognition of children with specific language impairment: effects of response modality. Journal of Speech, Language, and Hearing Research, 36, 98-104.

Montgomery, J. W. (2000). Verbal working memory and sentence comprehension in children with specific language impairment. Journal of Speech, Language, and Hearing Research, 43, 293-308.

Montgomery, J. W. (2003). Working memory and comprehension in children with specific language impairment: what we know so far. Journal of Communication Disorders, 36, 221-231.

Moon, S. B., \& Byun, C. J. (2003). Korean Kaufman assessment battery for children $(K-A B C)$. Seoul: Hakjisa.

Paneque, O. M., \& Barbetta, P. M. (2006). A study of teacher efficacy of special education teachers of English language learners with disabilities. Bilingual Research Journal, 30, 171-193.

Paradis, J., Emmerzael, K., \& Duncan, T. S. (2010). Assessment of English language learners: using parent report on first language development. Journal of Communication Disorders, 43, 474-497.

Parra, M., Hoff, E., \& Core, C. (2011). Relations among language exposure, phonological memory, and language development in Spanish-English bilingually developing 2-year-olds. Journal of Experimental Child Psychology, $108,113-125$.

Pearson, B. Z., Fernandez, S. C., \& Oller, D. K. (1993). Lexical development in bilingual infants and toddlers: comparison to monolingual norms. Language Learning, 43, 93-120.

Petitto, L. A., \& Holowka, S. (2002). Does early simultaneous bilingual language exposure cause children to be language delayed and confused: special insights from bilingual babies and young children acquiring a signed and a spoken language. Sign Language Studies, 3, 4-33.

Poppen, R., Stark, J., Eisenson, J., Forrest, T., \& Wertheim, G. (1969). Visual sequencing performance of aphasic children. Journal of Speech, Language, and Hearing Research, 12, 288-300.

Prior, A., \& Gollan, T. H. (2011). Good language-switchers are good taskswitchers: evidence from Spanish-English and Mandarin-English bilinguals. Journal of the International Neuropsychological Society, 17, 682-691.

Scott, W. A. (1962). Cognitive complexity and cognitive flexibility. Sociometry, 25, 405-414.

Shriberg, L. D., \& Kwiatkowski, J. (1994). Developmental phonological disor- ders I: a clinical profile. Journal of Speech, Language, and Hearing Research, 37, $1100-1126$.

Spaulding, T. J. (2010). Investigating mechanisms of suppression in preschool children with specific language impairment. Journal of Speech, Language, and Hearing Research, 53, 725-738.

Stokes, S. F., Wong, A. M., Fletcher, P., \& Leonard, L. B. (2006). Nonword repetition and sentence repetition as clinical markers of specific language impairment: the case of cantonese. Journal of Speech, Language, and Hearing Research, 49, 219-236.

Swanson, H. L., \& Sachse-Lee, C. (2001). A subgroup analysis of working memory in children with reading disabilities domain-general or domainspecific deficiency? Journal of Learning Disabilities, 34, 249-263.

Vigotsky, L. S. (1962). Thought and language. Cambridge, MA: MIT Press.

Wellman, H. M. (1990). The child's theory of mind. Cambridge, MA: MIT Press.

Welsh, M. C., \& Pennington, B. F. (1988). Assessing frontal lobe functioning in children: views from developmental psychology. Developmental Neuropsychology, 4, 199-230.

Wertsch, J. V. (1998). Mind as action. New York, NY: Oxford University Press. Williams, D., Stott, C. M., Goodyer, I. M., \& Sahakian, B. J. (2000). Specific language impairment with or without hyperactivity: neuropsychological evidence for frontostriatal dysfunction. Developmental Medicine \& Child Neurology, 42, 368-375.

Windsor, J., \& Kohnert, K. (2004). The search for common ground. Part I: Lexical performance by linguistically diverse learners. Journal of Speech, Language, and Hearing Research, 47, 877-890.

Windsor, J., Kohnert, K., Lobitz, K. F., \& Pham, G. T. (2010). Cross-language nonword repetition by bilingual and monolingual children. American Journal of Speech-Language Pathology, 19, 298-310.

Windsor, J., Kohnert, K., Loxtercamp, A. L., \& Kan, P. (2008). Performance on nonlinguistic visual tasks by children with language impairment. $A p$ plied Psycholinguistics, 29, 237-268.

Yang, Y., Yim, D., \& Bae, K. (2015). Predictors of word learning in children with specific language impairment. Communication Sciences \& Disorders, 20, $1-12$.

Yang, Y., Yim, D., Kim, S., \& Han, J. (2013). The relationship among receptive vocabulary, non-word repetition, and quick incidental learning in preschoolers with and without delay in vocabulary development. Communication Sciences \& Disorders, 18, 379-391.

Yim, D. (2011). The use of nonlinguistic statistical learning as a clinical mark- 
er in bilingual children. Korean Journal of Communication Disorders, 16, $13-22$.

Yim, D., Kim, S. Y., \& Yang, Y. (2015). Factor analysis of working memory tasks based on information processing characteristics: predictive factors of receptive vocabulary and quick incidental learning in children with typically developing and receptive vocabulary delay. Communication Sciences \& Disorders, 20, 304-318.

Yim, D., Kim, Y. T., \& Yang, Y. (2016). Exploring the utility of verbal and visuospatial working memory for identifying children with language impairment. Communication Sciences \& Disorders, 21,193-205.

Yim, D., \& Rudoy, J. (2013). Implicit statistical learning and language skills in bilingual children. Journal of Speech, Language, and Hearing Research, 56, 310-322.

Yim, D., Yang, Y., \& Kim, S. (2015). Domain-specific working memory performance in children with and without specific language impairment.
Communication Sciences \& Disorders, 20, 13-23.

Yim, D., Yoon, S., \& Lee, J. (2016). Receptive vocabulary assessment in Korean-English bilingual children: cross-linguistic investigations. Communication Sciences \& Disorders, 21, 131-138.

Zelazo, P. D. (2006). The Dimensional Change Card Sort (DCCS): a method of assessing executive function in children. Nature Protocols, 1, 297-301.

Zelazo, P. D., \& Frye, D. (1997). Cognitive complexity and control: a theory of the development of deliberate reasoning and intentional action. In M. I. Stamenov (Ed.), Language structure, discourse and the access to consciousness (pp. 113-153). Philadelphia, PA: John Benjamins Publishing.

Zimmerman, B. J. (1994). Dimensions of academic self-regulation: a conceptual framework for education. In D. H. Schunk \& B. J. Zimmerman (Eds.), Self-regulation of learning and performance: issues and educational applications (pp. 3-21). Hillsdale, NJ: Lawrence Erlbaum Associates. 
Appendix 1. 한국어 비단어 따라말하기 과제 기록지

\begin{tabular}{|c|c|c|c|}
\hline 아동명(성별) & 생년월일(생활연령) & \\
\hline 검사자 & & 검사일 & \\
\hline
\end{tabular}

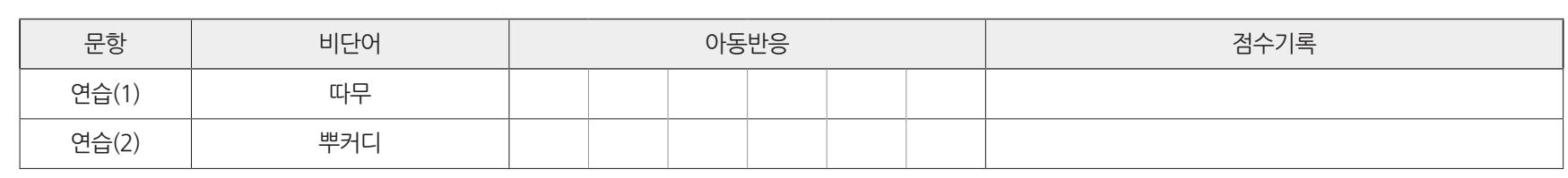

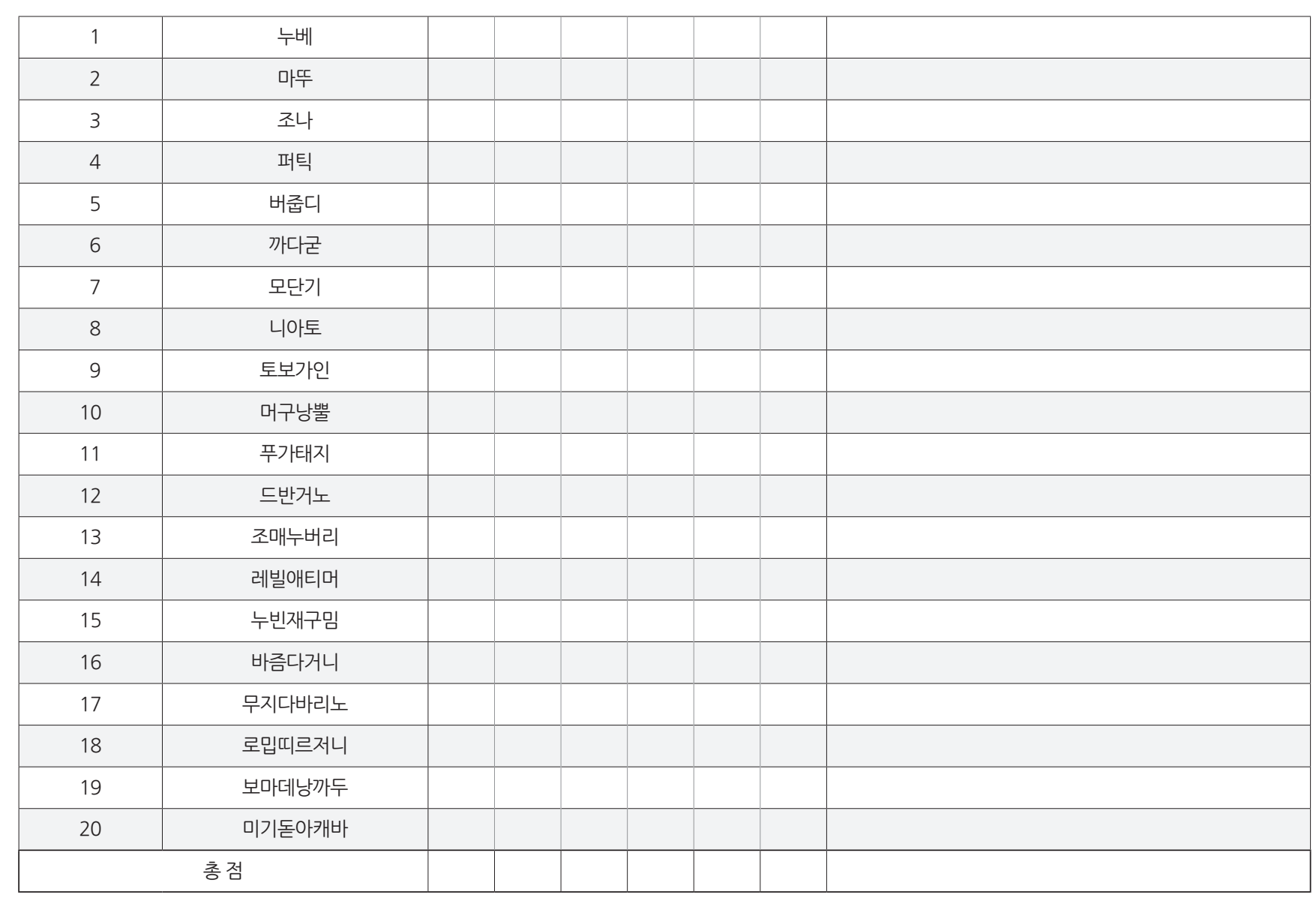


Dongsun Yim, et al. • Executive Function in Bilinguals with Vocabulary Delay

Appendix 2. English non-word repetition scoring sheet

\begin{tabular}{|c|c|c|c|}
\hline Examinee (sex) & DOB (C.A) & \\
\hline Examiner & & Test Date & \\
\hline
\end{tabular}

\begin{tabular}{|c|c|c|c|}
\hline Item & Non-word & Response & Score \\
\hline Practice (1) & deik & & \\
\hline Practice (2) & pei pub & & \\
\hline
\end{tabular}

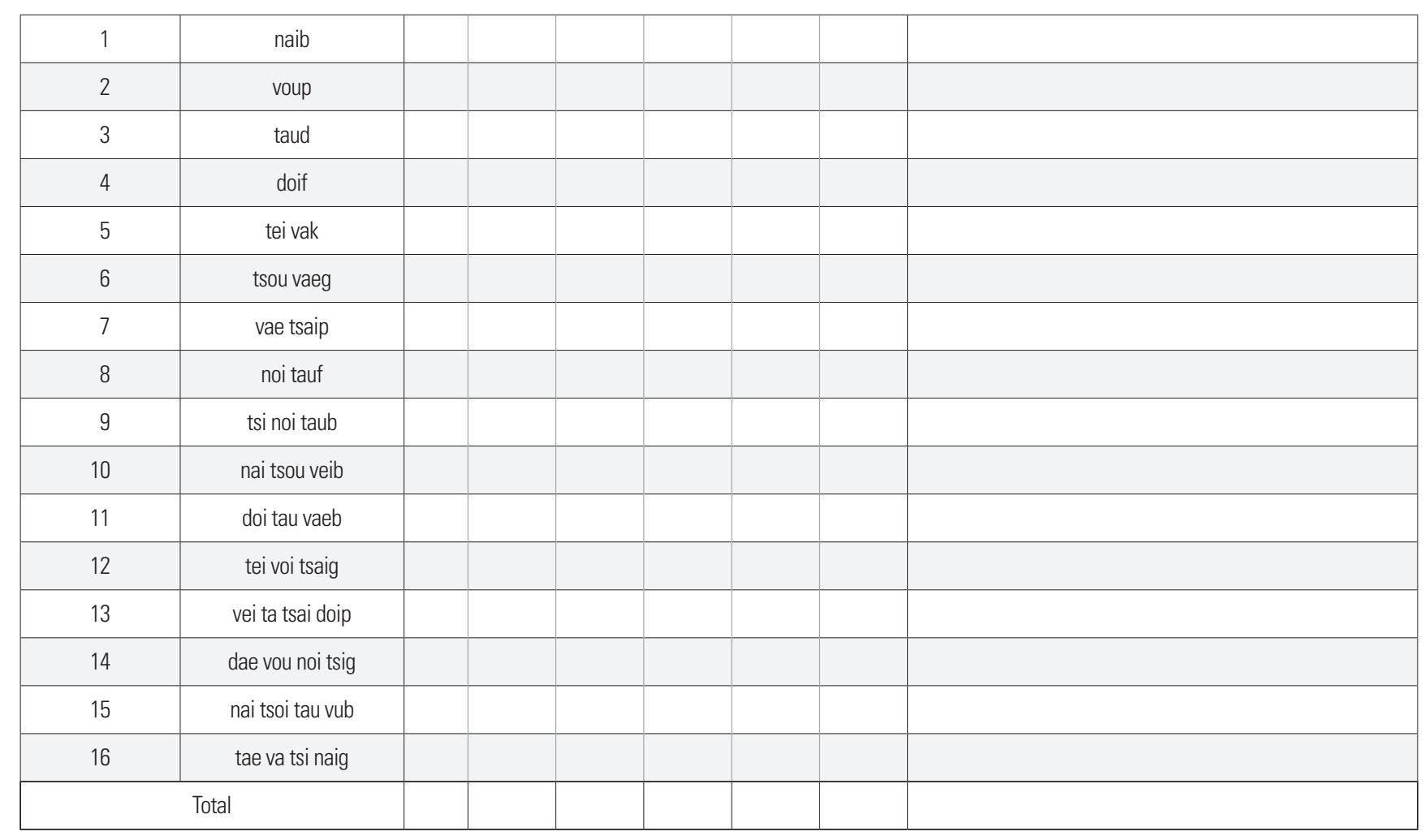




\section{국문초록}

\section{한국어-영어 이중언어사용 아동의 어휘발달지연 유무에 따른 집행기능 비교}

임동선 · 조연주 · 한지윤 · 성지민

이화여자대학교 대학원 언어병리학과

배경 및 목적: 본 연구는 이중언어사용 아동의 언어능력과 집행기능을 구성하는 전환능력 및 작업기억 간의 관계를 검토하고자 하였 다. 방법: 서울지역에 거주하며 한국어-영어를 사용하는 만 6-9세 이중언어사용 아동 33명(일반 19명, 어휘발달지연 14 명)을 대상으로 전환과제, 비언어성 작업기억과제로 매트릭스, 언어성 작업기억과제로 한국어, 영어 비단어 따라말하기를 실시하였다. 일원배치 분산 분석으로 집행기능에서 집단 간 수행을 비교하고, Pearson 상관분석으로 집단 내 과제 간 상관을 검토하였다. 결과: 어휘발달지연 집단 은 일반 집단에 비해 전환과제와 비언어성 작업기억과제에서 유의하게 낮은 수행을 보였다. 또한 영어 비단어 따라말하기에서 문항정확 도보다 자음정확도로 수행을 비교하였을 때 집단 간 수행 차가 유의하였다. 각 집단 내 과제 간 상관을 검토해 본 결과 일반 집단에서는 $\mathrm{REVT}$ 합산점수가 비언어성 및 언어성 작업기억(한국어)과 유의한 상관을 보였으며, 어휘발달지연 집단의 경우 REVT 합산점수가 비 언어성 및 언어성 작업기억(영어)과 유의한 상관을 이루었다. 논의 및 결론: 어휘발달지연 집단은 일반 집단과 비교하여 집행기능 하위 과제의 수행력이 낮으며, 이들이 언어영역뿐만 아니라 비언어적 인지처리영역에서도 어려움이 있는 것으로 나타났다. 따라서 이중언어 사용 어휘발달지연 아동을 대상으로 언어 평가 및 중재를 계획할 때에 집행기능과 같은 인지능력을 고려할 것을 권고하는 바이다.

핵심어: 이중언어 집행기능, 전환기능, 작업기억, 이중언어사용 어휘발달지연

본 연구는 2015년도 이화여자대학교 교내 연구비 지원에 의해 수행되었음.

\section{참고문헌}

김영태, 홍경훈, 김경희, 장혜성, 이주연(2009). 수용·표현 어휘력검사(REVT). 서울: 서울장애인종합복지관.

문수백, 변창진(2003). K-ABC 교육·심리측정도구(Korean-Kaufman assessment battery for children). 서울: 학지사.

양윤희, 임동선, 김신영, 한지윤(2013). 학령 전 어휘발달지체 및 일반 아동의 비단어 따라 말하기, 빠른 우연학습(Quick Incidental Learning)과수용

어휘와의 관계. 언어청각장애연구, $18,379-391$.

양윤희, 임동선, 배경란(2015). 학령기 단순언어장애 아동의 어휘학습 예측요인: 의미점화 및 간섭 효과. 언어청각장애연구, 20, 1-12.

이귀옥, 이혜련(2005). 아동의 이중언어경험과 상위인지능력의 관계. 한국심리학회지: 발달, 18, 105-119.

임동선, 김신영, 양윤희(2015). 정보처리 특성에 따른 작업기억 과제의 탐색적 요인분석: 일반아동 및 수용어휘지체 아동의 수용어휘력 및 빠른우연

학습 예측요인. 언어청각장애연구, 20,304-218.

임동선, 양윤희, 김신영(2015). 단순언어장애 아동과 일반 아동의 작업기억 제시방식 및 과제유형에 따른 수행능력 비교. 언어청각장애연구, 20, 13-

23.

임동선, 윤사라, 이지연(2016). 교차언어 연구를 통한 한국어-영어 이중언어아동의 수용어휘력 평가. 언어청각장애연구, 21, 131-138.

홍선미, 임동선(2014). 학습 및 기억과제를 통한 이중언어아동의 언어발달지체 평가. 언어청각장애연구, 19,31-44.

황민아(2015). 일반아동의 비단어 따라말하기. 언어청각장애연구, 20, 374-385. 